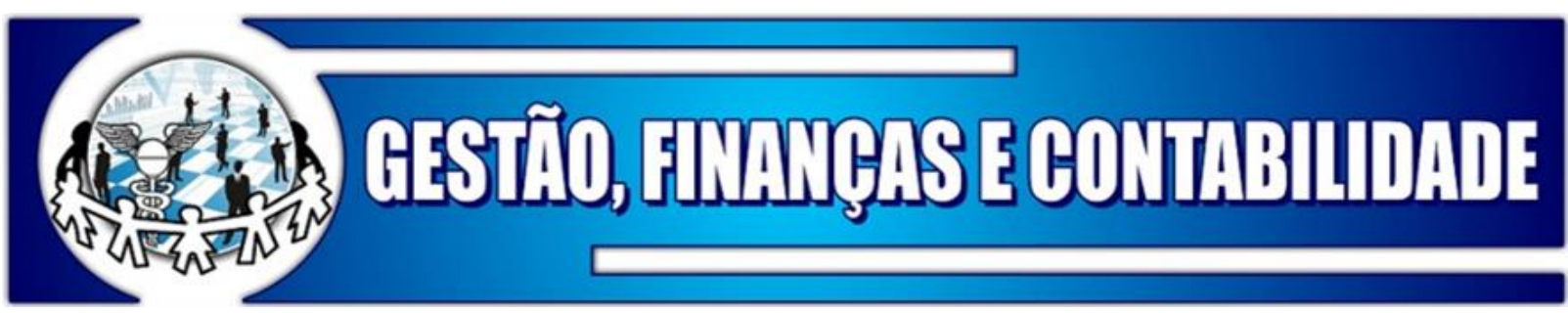

\title{
AGRESSIVIDADE FISCAL DE EMPRESAS BRASILEIRAS COM TRANSAÇÕES ENTRE PARTES RELACIONADAS NO EXTERIOR
}

\section{TAX AGGRESSIVENESS OF BRAZILIAN COMPANIES WITH RELATED-PARTY TRANSACTIONS ABROAD}

\section{LA AGRESIVIDAD FISCAL DE LAS EMPRESAS BRASILEÑAS CON TRANSACCIONES DE PARTES VINCULADAS EN EL EXTRANJERO}

Antonio Lopo Martinez

https://orcid.org/0000-0001-9624-7646

Doutor em Contabilidade na Universidade de São Paulo (USP) Doutorando em Direito na Faculdade de Direito da Universidade de Coimbra

E-mail: antoniolopomartinez@gmail.com

Joy Dawey Ribeiro da Silva

https://orcid.org/0000-0002-6742-8031

Professor da Faculdade Boa Viagem - FBV-DeVry, Doutorando em Ciências Contábeis (UFPE) Mestre em Contabilidade (Fucape/ES) E-mail: joyribeiro@ hotmail.com

\section{RESUMO}

O presente estudo tem como objetivo mensurar a agressividade fiscal de empresas brasileiras com transações entre partes relacionadas no exterior, identificando se tais empresas são mais agressivas comparado as que não têm investimentos no exterior, utilizando a ETR (Taxa Efetiva de Tributação) como medida de agressividade. Como técnica de análise é utilizada a regressão quantílica, a qual possibilita a análise de diferentes quantis da distribuição das variáveis dependentes. As hipóteses testadas verificam a relação entre a agressividade fiscal e a participação de investimento, controlando a sua relevância (peso) no total dos ativos da empresa. Os resultados evidenciaram a existência de uma relação positiva entre a agressividade tributária e a presença de investimentos no exterior. Essa relação, entretanto, não é constante ao longo de todos os níveis de agressividade tributária e do peso dos investimentos no estrangeiro no total dos investimentos do grupo econômico.

Palavras-chave: Agressividade Tributária; Regressão Quantílica; Effective Tax Rate; Partes Relacionadas.

\section{ABSTRACT}


Martinez e Silva (2019)

Agressividade Fiscal de Empresas Brasileiras com

Transações entre Partes Relacionadas no Exterior

The present study aims to measure the fiscal aggressiveness of Brazilian companies with transactions between related parties abroad, whose question is whether such firms are more aggressive thanthose who do not have overseas investments, using the ETR- Effective taxation as a measure of tax aggressiveness. As a technique for analyzing tax aggressiveness, Quantileregression is used, which allows the analysis of different quantiles of the distribution of dependent variables. The hypothesis tested verifies the relationship between tax aggressiveness and investment participation abroad, controlling its relevance (weight) in the company's total assets. The results showed the existence of a positive relationship between tax aggressiveness and the presence of overseas investments. However, this relationship is not constant throughout all levels of tax aggression and the weight of investments abroad in the total investment of the economic group.

Key words:Tax Aggressiveness; Quantile regression; Effective Tax Rate; Related parts.

\section{RESUMEN}

El presente estudio tiene como objetivo medir la agresividad fiscal de las empresas brasileñas con transacciones entre partes relacionadas en el extranjero, cuya pregunta es si esas empresas son más agresivas que las que no tienen inversiones en el extranjero, utilizando el ETRImposición efectiva como medida de agresividad fiscal. Como técnica de análisis de la agresividad fiscal se utiliza la regresión de Cuantile, que permite analizar diferentes cuantiles de la distribución de las variables dependientes. La hipótesis comprobada verifica la relación entre la agresividad fiscal y la participación en inversiones en el extranjero, controlando su relevancia (peso) en el total de activos de la empresa. Los resultados mostraron la existencia de una relación positiva entre la agresividad fiscal y la presencia de inversiones en el exterior. Sin embargo, esta relación no es constante en todos los niveles de agresión fiscal y el peso de las inversiones en el extranjero en la inversión total del grupo económico.

Palabras clave: Agresividad fiscal; Regresión de cuantías; Tasa impositiva efectiva; Partes relacionadas.

\section{INTRODUÇÃ̃O}

O objetivo da pesquisa é mensurar a agressividade fiscal das empresas brasileiras que têm transações com partes relacionadas no exterior. O cenário econômico em que as empresas estão inseridas faz com que sempre busquem inovações para que consigam manter uma sustentabilidade permanente e consolidada. Um exemplo de inovação e oportunidade é o que se percebe numa relação de investimento entre partes relacionadas.

Segundo Glaser (2010, p. 36), dentre as opções utilizadas no intuito de realizar planejamento tributário, seria pela utilização da combinação de negócios entre as empresas, a mesma pode melhorar o desempenho operacional e financeiro. Uma das maneiras de enfrentamento junto à concorrência, manutenção da sobrevivência econômica, seria por meio das transações comerciais entre partes relacionadas, pois implica em trocas significativas de elementos fundamentais que consolidam a robustez institucional (MAGRO;TELÓ, 2011, p. 13).

A melhoria nos resultados da empresa decorre da utilização de transações com partes relacionadas situadas em diferentes países, pois existe a oportunidade de explorar diversas alíquotas tributárias, reduzindo a base de cálculo a ser tributada (RATHKE; SARQUIS, 2014, p. 3). Conforme Clausing (2006, p. 272), em sua pesquisa sobre empresas norte-americanas, verificou um volume maior de transações com partes relacionadas em regiões que possuíam baixa carga tributária, desse modo, conseguiam um melhor resultado do lucro empresarial.

Revista de Gestão, Finanças e Contabilidade - v. 9, n. 1, p. 4-16, jan./abr. 2019 ISSN 2238-5320, UNEB, Salvador/BA 
Martinez e Silva (2019)

Agressividade Fiscal de Empresas Brasileiras com

Transações entre Partes Relacionadas no Exterior

Dharmapala e Riedel (2013, p. 99), analisaram as alterações significativas dos resultados econômicos das empresas controladoras europeias e constataram que as mesmas derivaram de transações com partes relacionadas as quais situam-se em países cujas alíquotas tributárias são inferiores com relação às alíquotas dos países investidores.

Existe na atualidade um crescente interesse nos temas associados a agressividade tributária e ao planejamento tributário, tendo a temática obtido ainda mais destaque nos últimos anos face uma combinação de fatores políticos, econômicos e tecnológicos, que têm impulsionado o foco do interesse público para as decisões corporativas, em especial aquelas relativas a tributação (GUENTHER; MATSUNAGA;WILLIAMS, 2017; Wilde \& Wilson, 2018).

O estudo busca contribuir a esclarecer uma lacuna ainda existente, relacionada ao possível efeito de um planejamento tributário internacional e consequências na agressividade fiscal de empresas brasileiras com transações entre partes relacionadas no exterior.

$\mathrm{Na}$ sequência será revisado o referencial teórico no tocante a agressividade fiscal e suas relações com as transações com partes relacionadas, posteriormente será exposta a metodologia utilizada na investigação e discutidos os resultados encontrados, encerrando com a apresentação das conclusões principais.

\section{REVISÃO DA LITERATURA}

Na revisão da literatura serão discutidos o que vem a ser Partes Relacionadas e como esta relaciona-se com as atividades de planejamento tributário. Em que medida a utilização de Partes Relacionadas propicia oportunidade para uma maior agressividade tributária.

\subsection{Partes relacionadas}

Os elementos que compõem as Partes Relacionadas podem ser uma entidade, pessoa física ou membro da família dessa pessoa física. Uma característica dessa relação é que as partes (investidas) remetem informações às empresas investidoras na forma de demonstrações contábeis (CPC 05 - R1). Essas transações com partes relacionadas ocorrem porque as investidoras buscam atividade complementar, fornecimento de matéria prima, tecnologia e aumentar participação no mercado decorrente da estratégia de negócios (JUNIOR; OLIVEIRA, 2010, p. 26). As ações resultantes de transações com partes relacionadas implicam em transferência de recursos, serviços e obrigações entre os envolvidos.

Pesquisas internacionais concluem que essas transações são benéficas para o negócio do grupo econômico (SOUZA; KNUPP; BORBA, 2013, p.124). Segundo Magalhães, Pinheiro e Lamounier (2011, p.23), desenvolver transações comerciais com partes relacionadas permite um maior grau de liberdade e flexibilidade para as empresas se comparada com as empresas não relacionadas, sendo considerada uma característica normal dos negócios. De acordo com Souza (2014, p.103) as transações com maior predominância entre partes relacionadas ocorrem com as empresas controladas, tendo ênfase à produção operacional e financeira, cujas atividades contemplam locações de bens móveis e imóveis, compras e vendas de ativos e empréstimos.

\subsection{Planejamento tributário}

A tributação no Brasil é altamente complexa, envolvendo vários tipos de custos (tributários e não tributários), os quais atingem as organizações, limitando o crescimento e absorvendo grande parte do faturamento e do lucro (SANTIAGO;SILVA, 2006, p. 24). Segundo Nascimento e Reginato (2013, p. 265), planejamento tributário consiste em avaliar o 
impacto da produção, vendas e prestação de serviços na carga tributária empresarial, buscando amenizar de maneira legal, um esforço financeiro desnecessário e exagerado.

O Planejamento Tributário surgiu como uma técnica de especialização em busca do mais alto grau de eficiência por meio da integração multidisciplinar, que convivem no cenário macroeconômico mundial, no intuito de aperfeiçoar a operacionalização da produção em sentido genérico, e também atender exigências legais voltadas para o âmbito tributário. Para a pessoa jurídica, o planejamento tributário representa a sobrevivência no mundo dos negócios moderno, em que a concorrência é muito alta. Desta forma, uma obrigação do administrador é identificar oportunidades para estimular a eficiência tributária.

Shevlin (1999, p. 1) afirma que a pesquisa em planejamento tributário examina as manifestações e as influências das regras tributárias frente as empresas e indivíduos na condução de suas vidas. A existência de um equilíbrio entre os diversos conhecimentos e suas aplicações, tende a proporcionar um modelo de consistência organizacional, produzindo segurança econômica a cadeia de valor (todas as partes) em que a entidade esteja inserida, e assim, sucessivamente ocorrerá com as demais que também optem por essa maneira de se estruturar. A alta carga tributária que se faz presente nos negócios e a grande extensão da legislação que regulamenta a tributação são os motivos que mais se destacam pela aplicação do planejamento tributário (BORGES, 2015, p.37).

O planejamento tributário deve ser encarado de maneira dinâmica, científica e permanente, sendo a economia dos tributos explícitos o seu grande objetivo. Gallo (2007, p. 45), esclarece que o planejamento tributário ameniza a carga tributária, é como se a base de cálculo a ser tributada fosse reduzida, impactando positivamente na eficiência tributária. A técnica pode ser aplicada em rendas corporativas e pessoais. Os custos necessitam de uma atenção especial, uma vez que sendo mal gerenciados podem provocar o desequilíbrio econômico-financeiro da instituição. Esta preocupação foi levantada por Calijuri (2009, p. 67), que pontuou elementos do patrimônio potencialmente depreciados pelos tributos, quais sejam os preços dos ativos, retorno dos investimentos ou até mesmo a influência na determinação da estrutura de capital das empresas.

Em suma, o planejamento tributário é a ação respaldada no ordenamento jurídico, cujo objetivo é a redução do pagamento do tributo, visto que a eficiência nos custos tributários fortalece a estrutura financeira das empresas.

\subsection{Agressividade fiscal}

Conforme Martinez e Ramalho (2014, p.1), agressividade fiscal provoca uma acentuada redução da base de cálculo a ser tributada, utilizando-se de técnicas inerentes ao planejamento tributário, podendo ser consideradas legais ou ilegais. Por meio da agressividade fiscal, busca-se a redução da base tributável aplicando técnicas de planejamento tributário, todavia, as ações agressivas correm o risco de serem entendidas como práticas ilícitas (CHEN; CHEN; CHENG;SHEVLIN,2010, p. 45).

Frischmann, Shevlin e Wilson (2008, p. 264) definem agressividade fiscal como um alto empenho pela busca de posições fiscais significativas, porém, com baixa sustentação legal. Outra definição é dada por Lisowsky, Robinson e Schmidt (2010, p. 11), como um conjunto de atividades de evasão fiscal, ou seja, ações pouco legítimas, utilizando-se de paraísos fiscais de maneira intensa. A busca pela redução dos custos tributários ocorre em vários países, prova disso é a estratégia de postergação do pagamento do tributo ocorrida nos Estados Unidos, com transações entre partes relacionadas no exterior, de acordo com Taylor, Richardson e Lanis (2015, p. 28), as multinacionais americanas utilizam-se dos ganhos de 
Martinez e Silva (2019)

Agressividade Fiscal de Empresas Brasileiras com

Transações entre Partes Relacionadas no Exterior

suas subsidiárias no exterior com o propósito de adiar a tributação doméstica, pois a tributação só ocorrerá quando da repatriação dos lucros.

Martinez \&Dalfior (2015) informa que o percentual legal dos tributos que incidem sobre o lucro contábil das empresas é cerca de 34\%, e que as empresas consideradas agressivas são as que atingem um índice menor que este valor de referência. Estamos cientes de que na seara tributária existem muito mais tributos além dos que incidem sobre o lucro contábil. Classificar de maneira absoluta uma empresa como sendo agressiva apenas quando alcança a redução do percentual apresentado acima (MARTINEZ;DALFIOR, 2015), poderia soar como um exagero, desse modo reconhecemos que a classificação é imperfeita, todavia, embasado na teoria apresentada, decorrente das pesquisas analisadas e por falta de uma classificação que seja mais próxima da realidade do cenário brasileiro - quanto maior a tributação sobre o lucro, maior será o endividamento (IUDÍCIBUS;POHLMANN, 2010, p.1) - e por analogia quanto menor a tributação incidente sobre o lucro, mais agressiva a empresa, sendo assim, pelo exposto utilizaremos a mesma classificação na pesquisa.

A temática de agressividade tributária tem ganho maior visibilidade na literatura brasileira face ao aumento da frequência e volume de publicações relativas a pesquisas e investigações de natureza empírica contábil que apreciam as causas e consequências da agressividade fiscal (CHIACHIO; MARTINEZ, 2019; LOPO MARTINEZ; FERREIRA, 2019; LOPO MARTINEZ; SALLES, 2018; LOPO MARTINEZ; SILVA, 2020; MARTINEZ; NOBRE, 2018; MARTINEZ; RODRIGUES. 2020).

\subsection{Taxa Efetiva Tributária (ETR) conceito e aplicação}

O ETR (Effective Tax Rate) é uma despesa tributária, cuja função consiste em auxiliar na estimativa dos custos tributários da empresa. Existem elementos que devem ser analisados, como as diferenças temporárias e permanentes, pertencentes aos lucros contábil e fiscal (Scholes \& Wolfson, 1992, p.453).

Giannini e Maggiulli (2002, p.12) afirmam que a ETR pode ser adotada para se avaliar o real impacto da carga tributária das empresas, além de explicar os seus efeitos nas tomadas de decisão. A maioria dos trabalhos que envolvem agressividade fiscal utiliza a ETR como variável dependente (HANLON; HEITZMAN, 2010, p.131). Dalfior (2015, p. 18) esclarece que a taxa de imposto efetiva (Effective Tax Rate - ETR) é calculada por meio da divisão da soma do imposto de renda pessoa jurídica (IRPJ), e da contribuição social sobre o lucro (CSLL), pelo lucro antes dos impostos (LAIR). Portanto, a ETR é a taxa de imposto efetiva, medida utilizada para mensurar a efetiva carga tributária das empresas. Dunbar, Higgins, Phillips e Plesko (2010, p.21) afirmam que a taxa de imposto efetiva (Effective Tax Rate ETR) é uma métrica para a mensuração da agressividade tributária empresarial. Para Hanlon e Heitzman (2010, p.141), o cálculo da ETR não é singular, o que pode impactar sobre as questões de pesquisa, em resumo significa um cálculo que divide alguma estimativa de imposto por uma medida antes de impostos sobre os lucros ou sobre os fluxos de caixa. Uma possível maneira de praticar a agressividade fiscal é quando um grupo econômico intensifica as transações com partes relacionadas em diferentes países, pois a multinacionalidade possibilita alternativas para este aspecto tributário (TAYLOR et al., 2015, p.25).

Conforme pesquisa realizada por Rego (2003, p. 828), as empresas multinacionais, que atuam com operações estrangeiras em vários países, e que são maiores no tamanho, quando investem em economias de escala multinacional tendem a ter ETR menor, tais empresas utilizam esta opção para a realização de planejamento tributário. Taylor et al.(2015, p. 37) informam que as variáveis de controle: Size, Leverage, ROA, períodos, são aplicadas em pesquisas envolvendo partes relacionadas no âmbito da multinacionalidade. 
Martinez e Silva (2019)

Agressividade Fiscal de Empresas Brasileiras com

Transações entre Partes Relacionadas no Exterior

\subsection{Definições das hipóteses de pesquisa}

Diante do contexto e do problema de pesquisa apresentados, surgem, então, as hipóteses de pesquisa a seguir:

H1: A relação entre a agressividade e a participação de investimento é variável ao longo da amostra.

H2: Nas empresas mais agressivas, a presença de investimentos no exterior e a sua crescente relevância (peso), explicam uma maior agressividade.

As hipóteses apresentadas buscam esclarecer ao nível da amostra, se a existência de transações com partes relacionadas no exterior e os crescentes aumentos desses investimentos torna as empresas investidoras mais agressivas tributariamente.

\section{METODOLOGIA}

Segundo Cooper e Schindler (2003, p.136), um estudo descritivo atende os seguintes escopos: descrições de fenômenos associados à população alvo, estimar os indicadores associados às variáveis dessa população e as descobertas de associação entre diferentes variáveis. O presente estudo é de cunho descritivo, pois, tem a proposta de investigar o nível de agressividade fiscal das empresas que têm investimento externo ou não, e em seguida, estimar essa agressividade correlacionando-a com outras variáveis ou comparando-as.

Tabela 1 - Processo de Formação e Composição da Amostra

\begin{tabular}{lc}
\hline \multicolumn{1}{c}{ Descrição } & Quantidade \\
\hline Total de empresas já excluídas as financeiras & 350 \\
(x) Quantidade de períodos (anos) & 05 \\
(=) Quantidade de observações possíveis & 1750 \\
(-) Exclusão de empresas com dados insuficientes & $(152)$ \\
(-) Exclusão de empresas com dados discrepantes & $(05)$ \\
(=) Quantidade de observações utilizadas & 1593 \\
\hline
\end{tabular}

Fonte:Tabela elaborada pelos autores conforme dados da pesquisa

Para atingir os objetivos do estudo, os dados foram coletados no banco de dados do Economática ${ }^{\circledR}$ e nas Demonstrações Contábeis das empresas. A população amostral foi composta por 350 companhias não financeiras de capital aberto listadas na BM\&FBovespa (como se observa na Tabela 1) no período de 2011 a 2015 e ativas em todos os anos citados. Inicialmente, foram excluídas as empresas sem informações de pelo menos uma das variáveis em um determinado ano - exceto a variável que caracterizava o valor investido no exterior, após esses filtros a amostra reduziu para 198 empresas. Também foram excluídas empresas que exibiram dados discrepantes para variável ETR que poderiam desvirtuar as análises. A amostra final foi constituída por 193 empresas, sendo 135 empresas sem investimento externo e 58 com investimento externo.

A coleta de dados se deu por meio do Economática ${ }^{\circledR}$ e das demonstrações contábeis, em que se relacionou/calculou as variáveis explicativas: ativo total (Size), leverage, ROA, peso de investimento externo e a variável dependente ETR.

\subsection{Métodos estatísticos e comparação das regressões tradicional e quantílica}

Coletados e tratados os dados, aplicou-se a estatística descritiva para apresentar as variáveis do conjunto de dados. Tal técnica corresponde aos métodos que facilitam coletar, 
resumir, demonstrar e analisar um conjunto de dados (LEVINE, STHEPHAN, KREHBIEL, 2014 , p. 4). Nesse processo inicial busca-se avaliar a distribuição e o comportamento da dispersão das características por meio das medidas estatística.

De acordo com Gujarati (2011, p.39), a análise de regressão tradicional significa explicar uma variável dependente, utilizando-se de outras variáveis, que a princípio, tenham certo grau de aproximação, cujo intuito é a obtenção de um resultado próximo do estimado, uma média. A regressão linear tradicional possui limitações porque só apresenta uma reta de regressão para o caso da média, ao passo que a regressão quantílica divide a amostra em várias partes, permitindo se aprofundar na análise amostral fornecendo maior qualidade e segurança.

Koenker e Basset (1978, p.34), buscam aplicar a regressão quantílica para a estimativa de funções-modelo, em que quantis da distribuição condicional da variável de resposta são expressos como funções de co-variáveis observados. A regressão de quantis está gradualmente tornando-se uma estratégia global para completar a imagem de regressão (HALLOCK; KOENKER, 2001, p. 143 e 154).

Nesta pesquisa, de acordo com a literatura apresentada com os devidos argumentos, dividiremos a amostra em quantis $(10 \% ; 20 \% ; 30 \%$...), desse modo será possível uma análise mais aprofundada, o que acarretará mais segurança e qualidade no momento da divulgação dos resultados e responder a questão da pesquisa.

\subsection{Regressão quantílica}

A regressão quantílica proposta por Koenker e Basset (1978, p.34) foi utilizada para responder as hipóteses do estudo. Filho et al. (2009, p. 317), utilizaram-se da técnica de regressão quantílica porque permite estimar toda a distribuição condicional da variável a ser explicada, dividindo a amostra em vários quantis, podendo direcionar a análise para as informações de maior interesse convergente à pesquisa.

Silva (2013, p. 15) fez uso da regressão quantílica argumentando ser uma opção mais focada e que elimina possíveis outliers. Na sequência, Souza $(2010$, p. 12) em sua pesquisa sobre o consumo de energia elétrica e as variáveis socioeconômicas, cita que devido à aplicação da regressão quantílica foi possível mensurar, com mais segurança, o grau de impacto do consumo de energia elétrica sobre o PIB brasileiro.

Evidenciada a relevância do modelo quantílico e associado aos propósitos citados por Gujarati (2011, p.40), nesta pesquisa a regressão quantílica será aplicada para mensurar a agressividade fiscal representada pela variável ETR, das empresas brasileiras que realizam transações com partes relacionadas no exterior. O modelo populacional empregado para testar as hipóteses de estudo, é dado pela equação a seguir:

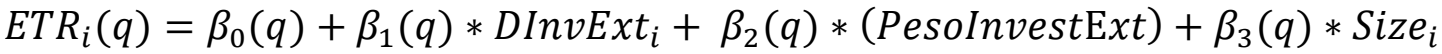

$$
\begin{aligned}
& +\beta_{4}(q) * R_{0} A_{i}+\beta_{5}(q) * \text { Leverege }_{i}+\beta_{t}(q) \text { DummyAno }_{t i}+\varepsilon_{i}
\end{aligned}
$$

onde,

$\mathrm{q}$ - representa quantil a ser estimado;

$E T R_{i}$ - Indicador de agressividade da i-ésima empresa;

DInvExt $\mathrm{i}_{\mathrm{i}}$ - Recebe um (1) se a i-ésima empresa faz investimento externo e zero (0) caso contrário;

PesoInvestExt $t_{i}-$ Valor de investimento externo da i-ésima empresa;

LogSize $_{i}$ - Logaritmo natural do Ativo total da i-ésima empresa.

$\mathrm{ROA}_{\mathrm{i}}-$ Retorno sobre o ativo da i-ésima empresa;

Revista de Gestão, Finanças e Contabilidade - v. 9, n. 1, p. 4-16, jan./abr. 2019 ISSN 2238-5320, UNEB, Salvador/BA 
Leverage $_{\mathrm{i}}$ - Alavancagem financeira da i-ésima empresa;

DummyAno ${ }_{t}-$ Representa o ano $t$;

Os coeficientes $\beta_{1}$ e $\beta_{2}$ são os coeficientes associados na busca por respostas às hipóteses do estudo. Para a hipótese $\mathrm{H} 1$, será avaliado o comportamento dos coeficientes (diferenças) nos modelos por quantis q, estimados separadamente. Para responder a hipótese H2, serão observados a significância dos coeficientes e a magnitude dos valores estimados.

\section{ANÁLISE DOS RESULTADOS}

As próximas duas subseções exibem os resultados das estatísticas descritivas da amostra e dos modelos estimados, este último com a proposta de avaliar se as empresas com participação de investimento são mais agressivas ou não.

\subsection{Caracterização da amostra}

A Tabela 1 apresenta a média das variáveis por setor, conglomerando o período entre 2011 e 2015, e a Tabela 2 as medidas descritivas por grupo - presença de investimento no exterior e sem presença de investimento no exterior.

Do total de 193, aproximadamente 33\% são empresas oriundas dos segmentos de Energia Elétrica, Comércio, Construção ou alimentos. Destes, é possível observar que incidiu com a menor média de ETR, o setor de construção civil, e a maior, o setor de alimentos e bebidas.

Ao analisar o tamanho da empresa (LogSize) por setor, nota-se que o setor de Energia Elétrica e Papel celulose incidiram com as maiores médias. Referente à alavancagem financeira (leverage), destacam-se, os setores de Transporte e Serviços e Papel e Celulose com maiores médias, em contrapartida, com menores médias, o setor de Eletroeletrônicos e Telecomunicações.

Tabela 2 - Médias das Variáveis Por Setor - 2011 a 2015

\begin{tabular}{lcccccc}
\hline \multicolumn{1}{c}{ Setor Economática } & $\mathrm{n}$ & $\mathrm{n} \%$ & \multicolumn{4}{c}{ Média } \\
\cline { 5 - 7 } & & & $\mathrm{ETR}$ & LogSize & $\mathrm{ROA}$ & Leverage \\
\hline Energia Elétrica & 21 & $10,9 \%$ & 0,3124 & 7,0851 & 0,0565 & 0,3357 \\
Comércio & 15 & $7,8 \%$ & 0,3457 & 6,5847 & 0,0537 & 0,2651 \\
Construção & 15 & $7,8 \%$ & 0,2705 & 6,5428 & 0,0649 & 0,3128 \\
Alimentos e Beb. & 12 & $6,2 \%$ & 0,3673 & 6,3169 & 0,0727 & 0,3908 \\
Siderur \& Metalur & 12 & $6,2 \%$ & 0,3640 & 6,2932 & 0,0758 & 0,4056 \\
Têxtil & 12 & $6,2 \%$ & 0,2967 & 6,7000 & 0,0761 & 0,2775 \\
Veículos e peças & 12 & $6,2 \%$ & 0,2175 & 6,1002 & 0,1136 & 0,2832 \\
Transporte Serviço & 10 & $5,2 \%$ & 0,3527 & 6,6396 & 0,0634 & 0,4983 \\
Petróleo e Gás & 5 & $2,6 \%$ & 0,3315 & 6,6376 & 0,0511 & 0,3417 \\
Química & 5 & $2,6 \%$ & 0,1334 & 6,7434 & 3,9006 & 0,2938 \\
Máquinas Indúst. & 4 & $2,1 \%$ & 0,2411 & 5,9795 & 0,1258 & 0,1983 \\
Mineração & 4 & $2,1 \%$ & 0,3154 & 6,6863 & 0,2315 & 0,1984 \\
Papel e Celulose & 4 & $2,1 \%$ & 0,8916 & 7,0629 & 0,0217 & 0,4398 \\
Software e Dados & 4 & $2,1 \%$ & 0,2303 & 5,8905 & 0,0578 & 0,2800 \\
Agro e Pesca & 3 & $1,6 \%$ & 0,2711 & 6,3225 & 0,0481 & 0,3821 \\
Eletroeletrônicos & 3 & $1,6 \%$ & 0,1713 & 6,0218 & 0,6604 & 0,0977 \\
Telecomunicações & 3 & $1,6 \%$ & 0,6084 & 6,0625 & 0,0819 & 0,1244 \\
Minerais não Met. & 2 & $1,0 \%$ & 0,3212 & 5,9337 & 0,0887 & 0,2272
\end{tabular}


Martinez e Silva (2019)

Agressividade Fiscal de Empresas Brasileiras com

Transações entre Partes Relacionadas no Exterior

\begin{tabular}{lcccccc} 
Outros & 47 & $24,4 \%$ & 0,3172 & 6,2430 & 0,0876 & 0,2645 \\
\hline Total & 193 & $100 \%$ & 0,3224 & 6,4667 & 0,1872 & 0,3079 \\
\hline
\end{tabular}

Fonte: Elaborado pelos autores.

A Tabela 3, ao mensurar as medidas da variável por grupo, destacam-se os seguintes pontos: ETR - médias e desvio padrão com valores semelhantes; já os quartis 0,40 e 0,60 apresentaram valores menores no grupo com presença de investimento no exterior; LogSize médias com proximidades e sem diferenças significativas nos quartis; ROA - a média bem inferior para os grupos com investimento externo, esse resultado não permanece quando avalia os quartis.

Vale observar que o grupo sem investimento apresentou maior variabilidade (desvio padrão) neste indicador; Leverage - no grupo com presença de investimento, permeou um grau de alavancagem financeira superior em todas as medidas quando comparado ao grupo sem presença de investimento.

Tabela 3 - Estatística Descritiva das Variáveis Por Grupo - 2011 a 2015

\begin{tabular}{|c|c|c|c|c|c|c|c|}
\hline \multirow{2}{*}{ Variável } & \multirow{2}{*}{ Grupo } & \multirow{2}{*}{ Média } & \multirow{2}{*}{$\begin{array}{l}\text { Desvio } \\
\text { Padrão }\end{array}$} & \multicolumn{4}{|c|}{ Quantil } \\
\hline & & & & 0,20 & $\mathbf{0 , 4 0}$ & 0,60 & $\mathbf{0 , 8 0}$ \\
\hline \multirow{3}{*}{ ETR } & Com Investimento & 0,3269 & 0,5732 & 0,0819 & 0,1829 & 0,2693 & 0,3529 \\
\hline & Sem Investimento & 0,3203 & 0,5640 & 0,0808 & 0,2104 & 0,2810 & 0,3423 \\
\hline & Geral & 0,3224 & 0,5666 & 0,0818 & 0,2024 & 0,2779 & 0,3455 \\
\hline \multirow{3}{*}{ Log Size } & Com Investimento & 6,6303 & 0,7723 & 5,9911 & 6,3988 & 6,7728 & 7,2168 \\
\hline & Sem Investimento & 6,3923 & 0,8456 & 5,8214 & 6,3430 & 6,6763 & 7,0545 \\
\hline & Geral & 6,4667 & 0,8304 & 5,8996 & 6,3677 & 6,7036 & 7,1003 \\
\hline \multirow{3}{*}{ ROA } & Com Investimento & 0,0961 & 0,1801 & 0,0202 & 0,0469 & 0,0722 & 0,1212 \\
\hline & Sem Investimento & 0,2287 & 3,0402 & 0,0169 & 0,0374 & 0,0615 & 0,1012 \\
\hline & Geral & 0,1872 & 2,5228 & 0,0177 & 0,0401 & 0,0647 & 0,1052 \\
\hline \multirow{3}{*}{ Leverage } & Com Investimento & 0,3476 & 0,1893 & 0,1885 & 0,3045 & 0,4050 & 0,4931 \\
\hline & Sem Investimento & 0,2899 & 0,2172 & 0,1044 & 0,2313 & 0,3236 & 0,4281 \\
\hline & Geral & 0,3079 & 0,2105 & 0,1257 & 0,2555 & 0,3422 & 0,4527 \\
\hline
\end{tabular}

Fonte: Elaborado pelo autor.

\subsection{Resultados}

Com o objetivo de analisar os resultados de maneira resumida, a seguir será apresentada a Tabela 4, em seguida, os devidos comentários.

Tabela 4-Resumo dos Modelos Estimados - Coeficientes

\begin{tabular}{llccccc}
\hline \multirow{2}{*}{$\begin{array}{l}\text { Tipo } \\
\text { Variável }\end{array}$} & \multirow{2}{*}{ de } & Variável & \multicolumn{5}{c}{ Quantil } \\
\cline { 3 - 7 } & & $\mathbf{1 0 \%}$ & $\mathbf{2 0 \%}$ & $\mathbf{3 0 \%}$ & $\mathbf{4 0 \%}$ & $\mathbf{5 0 \%}$ \\
\hline \multirow{2}{*}{ Proxy } & DummyInvExt & $-0,007$ & $-0,027^{* *}$ & $-0,055^{* * *}$ & $-0,055^{* *}$ & $-0,024$ \\
& PesoInvestExt & $0,003^{* *}$ & 0,002 & 0,002 & 0,002 & 0,002 \\
& LogSize & $0,029^{* *}$ & $0,049^{* *}$ & $0,050^{* *}$ & $0,052^{* *}$ & $0,053^{* *}$ \\
\multirow{2}{*}{ Controle } & ROA & $-0,030$ & 0,000 & $-0,001$ & $-0,002$ & $-0,002$ \\
& Leverage & $-0,016$ & $-0,025$ & 0,011 & 0,024 & 0,024 \\
\hline
\end{tabular}

Nota: ** Significativo ao nível de 5\%;

Fonte: Elaborado pelo autor 
A partir dos resultados encontrados, destacam-se as seguintes observações, ao analisar a regressão quantílica estimada para o quantil 0,10 ; evidencia-se que o volume estimado no exterior apresenta relação positiva com ETR, ou seja, empresa com nível de ETR de $10 \%$, ao investir no exterior, tornam-se menos agressivas.

Ao avaliar os resultados da regressão para os quantis 0,30 e 0,40 o impacto no ETR é maior, saindo de $2,7 \%$ (quantil 0,20 ) para $5,5 \%$, ou seja, havendo uma empresa com investimento no exterior nestes grupos, estas serão consideradas mais agressivas em torno de 5,5\%. Conforme Taylor, Richardson e Lanis (2015)as empresas que têm investimentos no exterior por meio de transações com partes relacionadas são mais agressivas.

A entidade mais agressiva tributariamente, ao realizar uma transação, assegura-se de que é utilizada em cada oportunidade a opção que permite minimizar os impostos. Quando opera em regimes onde a lei fiscal é incerta ou aberta a interpretação, tenderá a assumir a posição fiscal que lhe seja mais favorável. Ao estruturar suas transações sempre buscará as formas e alternativas que garantem a maior economia tributária.A busca de uma maior agressividade tributária não implica necessariamente em abusividade tributária, entretanto há o risco de que na redução deliberada das obrigações tributárias explícitas, a entidade adote medidas que abusem da lei, fraus legis, ou que a substância legal esteja em contradição com a forma legal.

No caso de transação com partes relacionadas no exterior é absolutamente razoável presumir que as empresas procuraram alocar os seus resultados nos países onde são menos tributados, ou alternativamente reconhecer as receitas onde são menos tributados e confrontar as despesas onde são mais tributados. As evidências empíricas documentadas neste trabalho deixam patente a maior agressividade fiscal daquelas empresas com participações internacionais.

\section{CONSIDERAÇÕES FINAIS}

Este estudo buscou mensurar a agressividade fiscal de empresas brasileiras com transações entre partes relacionadas no exterior. As hipóteses foram testadas em uma amostra constituída por 193 empresas, sendo 135 empresas sem investimento externo e 58 com investimento externo, coletadas no banco de dados do Economática. Foi utilizado no modelo de regressão uma variável dummy de investimento no exterior e uma variável de interação peso do investimento, além das variáveis de controle SIZE, ROA, Leverage e a dummy períodos. A agressividade fiscal foi mensurada pela utilização da variável dependente ETR.

Do total de 193 empresas, aproximadamente 33\% são empresas oriundas dos segmentos de energia elétrica, comércio, construção ou alimentos. Destes, é possível observar que incidiu com a menor média de ETR, o setor de construção civil e a maior, o setor de alimentos e bebidas.

Ao analisar o tamanho da empresa (LogSize), notam-se os setores de Energia Elétrica e Papel Celulose aparecem com as maiores médias. Referente à alavancagem financeira (Leverage), destacam-se os setores de Transporte, Serviços e Papel Celulose com maiores médias, em contrapartida com as menores médias, o setor de Eletroeletrônicos e Telecomunicações.

Os resultados da investigação evidenciaram a existência de uma relação positiva entre a agressividade tributária e a presença de investimentos no exterior. Essa relação, entretanto, não é constante ao longo de todos os níveis de agressividade tributária e do peso dos investimentos no estrangeiro no total dos investimentos do grupo econômico.

O estudo inova ao demonstrar a efetividade de um planejamento tributário internacional, evidenciada em termos médios por uma menor ETR naquelas empresas que

Revista de Gestão, Finanças e Contabilidade - v. 9, n. 1, p. 4-16, jan./abr. 2019 ISSN 2238-5320, UNEB, Salvador/BA 
mantem investimentos no exterior. A transações com partes relacionadas propiciam oportunidades e incentivos para a transferência de resultados entre fronteiras como a intenção de reduzir o ônus tributário.

Num contexto de BEPS (Base Erosion Profit Shifting) é razoável a preocupação das Autoridades Tributárias em verificar possíveis práticas abusivas na transferência de receitas para países e empresas no exterior com taxa marginal de tributação mais favoráveis que a nacional, e o trazer para o Brasil despesas que tem sua origem no exterior, mas que reduziriam o ônus tributário do grupo econômicos.

A temática de agressividade tributária tem se demonstrado muito profícua com questões ainda não plenamente resolvidas que podem ser de interesse para formuladores de políticas tributárias, reguladores, incluindo aí as autoridades tributárias, diretores de empresas, investidores e pesquisadores acadêmicos. No Brasil com as alterações recentes na sua legislação contábil tributária oferece oportunidade para investigações mais aprofundadas em torno dessas temáticas, sendo muito útil tanto internamente como no exterior (MARTINEZ, 2017).

O presente estudo pode contribuir com novas pesquisas relacionadas com os temas de planejamento tributário internacional, tais como ETR, agressividade fiscal, regressão quantílica e partes relacionadas. Propõe-se, para futuras pesquisas, a utilização de outras variáveis ou períodos, podendo usar as medidas deste trabalho e outras utilizadas pela literatura.

\section{REFERÊNCIAS}

CHEN, S.: CHEN, X.; CHENG, Q.; SHEVLIN, T. Are family firms more tax agressive than non-family firms? Journal of Financial Economics, 95(1), 41-61.2010.

CHIACHIO, V. F. DE O.; MARTINEZ. A. L. Efeitos Do Modelo de Fleuriet e Índices de Liquidez Na Agressividade Tributária. Revista de Administração Contemporânea 23(2):160-81. 2019.

CLAUSING, K. International tax avoidance and U.S. international trade. National Tax Journal, 59(2), 269-287.2006.

COMITÊ de Pronunciamentos Contábeis.Pronunciamento técnico CPC 05 Rl. Divulgação sobre Partes Relacionadas. Recuperado em 26 abril 2016, de http://www.cpc.org.br. 2010.

COOPER, D. R.; SCHINDLER, P. S.Métodos de Pesquisa em Administração(7 ed.). Tradução de Luciana de Oliveira da Rocha. Porto Alegre. Bookman. 2003.

DHARMAPALA, D.; RIEDEL, N. Earnings shocks and tax-motivated income-shifting: evidence from European multinationals. Journal of Public Economics, 97, 95-107. 2013.

DUNBAR A.; HIGGINS D.; PHILLIPS J.;PLESKO G. What do Measures of Tax Aggressiveness Measure? Proceedings of the National Tax Association Annual Conference on Taxation, pp.18-26.9p.2010.

FRISCHMANN, P. J.; SHEVLIN, T.; WILSON, R. Economic consequences of increasing the conformity in accounting for uncertain tax benefits. Journal of Accounting and Economics, 46(2), 261-278.2008.

GALLO, M. F. A relevância da abordagem contábil na mensuração da carga tributária das empresas. Tese (Doutorado) - Universidade de São Paulo - USP.2007. 
GUENTHER, D. A.; MATSUNAGA, S. R.;WILliAMS, B. M. Is Tax Avoidance Related to Firm Risk? Accounting Review, 92(1), 115-136. https://doi.org/10.2308/accr-51408. 2017.

GIANNINI, S.; MAGGIULLI, C.The Effective Tax Rates in the EU Commission Study on Corporate Taxation: Methodological Aspects, Main Results and Policy Implications. 2002.

Glaser, A. Reorganização Societária como forma de planejamento tributário. Dissertação (Mestrado) - UFRGS, Porto Alegre. 2010.

Gujarati, D. N. Econometria básica(5. ed.). São Paulo: Makron Books.2011.

HALLOCK, K. F.; KOENKER, R. Quantile Regression. Journal of Economic Perspectives, 15, 143-156. 2001.

HANLON, M.; HEITZMAN, S. A review of tax research. Journal of Accounting and Economics, 50(2), 127-178.2010.

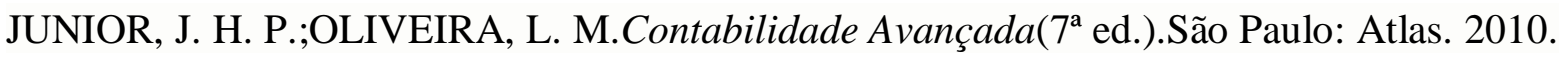

KOENKER, R.; BASSETT JR, G. Regression quantiles. Econometrica: journal of the Econometric Society, 33-50.1978.

LEVINE, D. M.; STHEPHAN, D. F.; KREHBIEL, T. C.; BERENSON, M. L.Estatística: teoria e aplicações: usando o Microsoft excel em português(trad. Teresa Cristina Padilha de Souza). Rio de Janeiro: LTC. 2014.

LISOWSKY, P.; ROBINSON, L.;SCHMIDT, A. An Examination of FIN 48: Tax Shelters, Auditor Independence, and Corporate governance. Working paper, University of Illinois at Urbana-Champaign, Tuck School of Business at Dartmouth, and Columbia University. 2010.

LOPO MARTINEZ, A.; FERREIRA. B. A. Business Strategy and Tax Aggressiveness in Brazil. Journal of Strategy and Management 12(4):522-35. 2019.

LOPO MARTINEZ, A., SALLES, A. F. Agressividade Tributária e Cash Holdings: Um Estudo Das Companhias Abertas Brasileiras. Revista de Contabilidade Da UFBA 12(3):4. 2018.

LOPO MARTINEZ, A., SILVA. R. Do Brazilian Publicly Traded Companies That Pay Less Tax Create More Jobs? REVISTA CATARINENSE DA CIÊNCIA CONTÁBIL 19:2894. 2020

MAGALHÃES, R. L. D. R.; PINHEIRO, L. E. T.;LAMOUNIER, W. M. Fatores que favorecem a compreensão da extensão da divulgação sobre partes relacionadas-estudo nas companhias listadas no novo mercado da BM\&FBovespa. Sociedade, Contabilidade e Gestão, 6(3).2011.

MAGRO, L.,TELÓ, A. As mudanças organizacionais em fusões e incorporações de empresas. Programa de Apoio à Iniciação Científica-PAIC. 2011.

MARTINEZ, A. L.; RODRIGUES. A. M. 2020. The Effect of Corporate Diversification on Tax Aggressiveness in Brazilian Companies. Contabilidade, Gestão e Governança 23(1):38-55. 2020.

MARTINEZ, A. L.; NOBRE, R. AGRESSIVIDADE FISCAL E O COMPORTAMENTO DA CHIEF EXECUTIVE OFFICER - CEO FEMININA NO BRASIL. Revista Mineira de Contabilidade 19(3):5-14. 2018. 
MARTINEZ, A. L. Agressividade Tributária: um survey da literatura. Revista de Educação e Pesquisa em Contabilidade. V. 11, Edição Especial, p. 108-126, 2017.

MARTINEZ, A. L., DALFIOR, M. D.Análise da agressividade fiscal entre controladoras e controladas. Revista da Receita Federal: estudos tributários e aduaneiros, Brasília-DF, v.2, n.1, p.344-362, jul./dez. 2015.

MARTINEZ, A. L.,RAMALHO, G. C. Family Firms and Tax Aggressiveness in Brazil. International Business Research, 7(3), 129.2014.

NASCIMENTO, A. M.;REGINATO,L. Controladoria: Um Enfoque Na Eficácia Organizacional. Editora Atlas SA.2013.

OLIVEIRA, G. P.Contabilidade tributária. São Paulo: Saraiva.2005.

RATHKE, A. A. T.; SARQUIS, R. W.Transfer Pricing e Income Shifting: evidências empíricas de empresas abertas brasileiras. Anais do Congresso USP de Controladoria e Contabilidade, 14. 2014.

SANTIAGO, M. F.; DA SILVA, J. L. G. Evolução e composição da carga tributária brasileira. Revista Brasileira de Gestão e Desenvolvimento Regional, 2(1).2015.

SCHOLES, M.; WOLFSON, M.; ERICKSON, M.; MAYDEW, E.; SHEVLIN, T.Taxes and Business Strategy: a Planning Approach. 2008.

SCHOLES, M. S.; WOLFSON, M. A. Reviewed Work: Taxes and Business Strategy: A Planning Approach. Review by: Theodore S. Sims, Emil M. Sunley National Tax Journal, Vol. 45, No. 4, pp. 451-455. December. 1992.

SHEVLIN, T. A Critique of Plesko's “An Evaluation of Alternative Measures of Corporate Tax Rates”. Social Science Research Network - SSRN. 1999.

SILVA, K. C. Gastos com saúde: estudo do impacto dos gastos na qualidade de prestação de serviço de saúde nos países em desenvolvimento. Dissertação (Mestrado) - Fundação Instituto Capixaba de pesquisas em contabilidade, economia e finanças - FUCAPE. 2013.

SOUZA, J. A. S.Transações com partes relacionadas: determinantes e impactos no desempenho das empresas. Dissertação (Mestrado)- Programa de Pós-Graduação em Ciências Contábeis, Universidade Federal do Espírito Santo - UFES. 2014.

SOUZA, M. M.; KNUPP, P. S.; BORBA, J. A. Características Associadas às Transações com Partes Relacionadas nas Empresas de Capital Aberto Brasileiras. Revista de Contabilidade, Gestão e Governança, 16(3). 2013.

SOUZA, R. Análise da relação entre o consumo de energia elétrica e variáveis socioeconômicas. Dissertação (Mestrado) - Fundação Instituto Capixaba de pesquisas em contabilidade, economia e finanças - FUCAPE.2010.

TAYLOR, G.; RICHARDSON, G.; LANIS, R. Multinationality, tax havens, intangible assets, and transfer pricing aggressiveness: An empirical analysis. Journal of International Accounting Research, 14(1), 25. 2015.

WILDE, J. H.; WILSON, R. J.Perspectives on Corporate Tax Planning: Observations from the Past Decade. The Journal of the American Taxation Association: Fall 2018, Vol. 40, No. 2, pp. 63-81. 2018. 